\title{
Traumas Infantis e as Relações Interpessoais e com o Bebê no Puerpério
}

\author{
Maira Noroefé dos Santos ${ }^{1}$ D, Tagma Marina Schneider Donelli(D) \\ Universidade do Vale do Rio dos Sinos, Porto Alegre-RS, Brasil
}

\section{RESUMO}

A importância das relações iniciais para formação do indivíduo já é reconhecida, bem como os prejuízos de uma criança viver experiências traumáticas nesse período fundamental do desenvolvimento. O objetivo aqui foi compreender como mães de crianças de até um ano de idade, que viveram traumas na infância, estabelecem as relações interpessoais e com seus filhos. Assim, foram utilizadas uma Ficha de Dados Sociodemográficos e Clínicos; Questionário Sobre Traumas na Infância (QUESI); Método de Rorschach; Entrevista sobre a maternidade e o relacionamento mãe-criança; Entrevista sobre História de Vida e Relações Atuais. Participaram três mulheres, primíparas, com idades entre 28 e 35 anos, com filhos entre 08 e 11 meses de vida. É um estudo descritivo, de abordagem qualitativa, feito por meio do Estudo de Casos Múltiplos. Como resultados, há evidência de prejuízo nas relações interpessoais, sugerindo que vivências traumáticas na infância deixam marcas permanentes na vida emocional de cada indivíduo.

Palavras-chave: trauma; relações interpessoais; relação mãe-bebê.

\section{ABSTRACT - Childhood Traumas and the Interpersonal and Baby Relationships in the Puerperium}

The importance of the initial relationships for the formation of the individual is already recognized, as are the losses suffered by a child that has traumatic experiences in this fundamental period of development. The aim of this study was to understand how mothers of children up to one year of age, who had experienced childhood traumas, established interpersonal relationships and relationships with their children. Accordingly, a Sociodemographic and Clinical Data Sheet; the Questionnaire on Trauma in Childhood (QUESI); the Rorschach Method; an Interview on Motherhood and Mother-Child Relationships; and an Interview on the Life History and Current Relationships were used. Three primiparous women, aged between 28 and 35 years, with children between 8 and 11 months of age participated. A descriptive, qualitative approach was employed, through the Multiple Case Study design. The results indicated evidence of impairment in interpersonal relationships, suggesting that traumatic childhood experiences leave permanent marks in the emotional life of each individual

Keywords: trauma; interpersonal relations; mother-baby relationship.

\section{RESUMEN - Traumas infantiles y relaciones interpersonales con los bebés en el Puerperio}

El peso de las relaciones iniciales para la formación del individuo y los traumas sufridos precozmente ya son reconocidos en este periodo fundamental del crecimiento. Así, el objetivo de este trabajo fue comprender cómo madres de niños hasta un año de edad, que sufrieron traumas en la infancia, establecen relaciones interpersonales con sus hijos. Se utilizó una ficha de datos sociodemográficos y clínicos; Cuestionario sobre Trauma en la Infancia (QUESI); Método de Rorschach; Entrevista sobre maternidad y relación madre-hijo; Entrevista sobre Historia de Vida y Relaciones Actuales. Participaron tres mujeres, primíparas, con edades entre 28 y 35 años, con niños entre 08 y 11 meses de edad. Se trata de un estudio con enfoque descriptivo y cualitativo, realizado a través del Estudio de Casos Múltiples. Como resultado, hay evidencias de perjuicios en las relaciones interpersonales, sugiriendo que las experiencias traumáticas de la infancia dejan marcas permanentes en la vida emocional de cada indivíduo.

Palabras clave: trauma; relaciones interpersonales; relación madre-bebé.

Buscando entender melhor o que permeia a construção das relações interpessoais, é essencial voltar até os primórdios da vida para refletir alguns pontos (Dias, 2012). Após décadas de estudos sobre a primeira infância sabe-se que as relações iniciais entre o bebê e seu cuidador são fundamentais para o desenvolvimento emocional, social e cognitivo (Winnicott, 1990/1988).

Muitos fatores podem interferir nesse processo, tais como o ambiente, a saúde psíquica da mãe, os cuidados primários, mas sem dúvida, a qualidade da relação que se

${ }^{1}$ Endereço para correspondência: Avenida Praia de Belas, 1520/401, 90110-000, Porto Alegre, RS. Tel.: (51) 99286-4878. E-mail: mairans1@hotmail.com Artigo derivado da Dissertação de mestrado de Maira Noroefé dos Santos com orientação de Tagma Marina Schneider Donelli, defendida em '2018' no programa de pós-graduação Programa de Pós-graduação em Psicologia Clínica da Universidade do Vale do Rio dos Sinos. 
estabelece entre o bebê e a mãe é fundamental, sendo esta considerada um fator de proteção ao desenvolvimento (Luthar \& Cicchett, 2000). Seus resultados são importantes, uma vez que deixarão marcas que irão influenciar na relação que a criança, no futuro, vai desenvolver, inclusive, com seus próprios filhos (Maldonado, 2002).

A partir da literatura é possível encontrar diversos estudos que ressaltam os danos que a criança pode sofrer quando exposta a situações de extrema vulnerabilidade. Algumas pesquisas apontam dificuldades relacionadas à agressividade, baixa autoestima, diminuição da qualidade e quantidade dos relacionamentos, comportamento autodestrutivo e impulsivo, comportamentos abusivos, uso de drogas, gravidez precoce, quadros de transtorno de humor depressivo, entre outros (Kerr-Corrêa, Tarelho, Crepaudi, Camiza, \& Villanassi; 2000; Mcwey, Cui, \& Pazdera, 2010).

O papel da mãe vai além do cuidado físico e das satisfações das necessidades fisiológicas do filho. Um encontro saudável gera ao recém-nascido a possibilidade de estabelecer uma relação harmoniosa e de confiança com sua mãe. Conforme a dupla vai aprimorando a sintonia, o encontro vai ganhando qualidade (Gutierrez \& Pontes, 2011). Entretanto, mães que apresentam um prejuízo emocional mostram maiores dificuldade para perceber e atender às demandas dos filhos, e pela falta de recursos emocionais tendem a ter mais dificuldades para lidar com eles (Felice, 2007; Klaus, Kennel, \& Klaus, 2000).

Em geral, toda mulher tende a se identificar com seus cuidadores, portanto, a relação estabelecida com os primeiros cuidadores merece ser amplamente estudada, uma vez que dá origem a matriz sobre o qual todos os vínculos posteriores se desenvolverão. São experiências que terão o poder de influenciar a saúde emocional do sujeito (Felice, 2007). Tendo em vista a importância das relações iniciais e do impacto destas na vida das pessoas, entende-se que é preciso ampliar os estudos de um tema de complexa compreensão. Assim, o objetivo deste trabalho foi compreender como mães de crianças de até um ano de idade, que viveram traumas na infância, estabelecem suas relações interpessoais e com seus filhos.

\section{Método}

\section{Participantes}

Participaram três mães primíparas, com idades entre 28 e 35 anos, com filhos de 8 a 11 meses de idade. A seleção das participantes foi feita por conveniência, respeitando os seguintes critérios de inclusão: (a) mães maiores de 18 anos; (b) primíparas; (c) filhos com idade máxima de doze meses de idade; (d) ter passado por alguma situação traumática em sua infância. Por trauma, foram considerados os relatos de vivências que apontassem abuso físico, abuso sexual, abuso emocional, negligência física e negligência emocional. No momento da coleta dos dados, por coincidência, todas participantes afirmaram estar fazendo psicoterapia individual de orientação analítica e acompanhamento psiquiátrico.

\section{Instrumentos}

Para coleta dos dados, foram utilizados os seguintes instrumentos: (a) Ficha de Dados Sociodemográficos e Clínicos; (b) Questionário sobre Traumas na Infância (QUESI); (c) Método de Rorschach - Sistema Compreensivo (Exner, 2003); d) Entrevista semiestruturada sobre História de Vida e Relações Atuais; e) Entrevista semiestruturada sobre a maternidade e o relacionamento mãe-criança (versão adaptada de NUDIF, 2008). Ambas as entrevistas foram realizadas pela pesquisadora e gravadas em áudio.

\section{Procedimentos}

Trata-se de um estudo descritivo, delineado em uma abordagem qualitativa e tem como procedimento o Estudo de Casos Múltiplos (Yin, 2001/1984). A pesquisa está amparada pela Resolução 510/2016 do Conselho Nacional de Saúde (2016) e aprovada pelo Comitê de Ética em Pesquisa da Universidade do Vale do Rio dos Sinos (UNISINOS). Destaca-se que os instrumentos utilizados não representaram prejuízos à saúde física e/ ou emocional dos participantes.

Após acesso às mães e esclarecimentos sobre a pesquisa via telefone, foi marcado o primeiro encontro em que houve a assinatura do TCLE - Termo de Consentimento Livre e Esclarecido, o preenchimento da ficha de dados sociodemográficos, a aplicação do questionário QUESI e a aplicação da entrevista História de Vida e Relações Atuais. No segundo encontro, deu-se a aplicação do Método de Rorschach e, no terceiro, foi feita a Entrevista sobre a Maternidade e o Relacionamento mãe-criança. Os encontros aconteceram, em média, no intervalo de um mês e houve três encontros ao total, com duração entre uma a três horas. Eles aconteceram na casa de duas das participantes e uma delas optou pelo encontro ser no consultório da pesquisadora.

\section{Análise de Dados}

Asinformações daFichade Dados Sociodemográficos e Clínicos auxiliaram no entendimento do contexto de vida de cada participante. O QUESI - Questionário Sobre Traumas na Infância foi levantado de acordo com o seu protocolo e utilizado para confirmar a presença de traumas na infância. Já o protocolo de respostas do Rorschach foi analisado e codificado por dois juízes independentes, treinados e com experiência na utilização do método e foi solicitado um terceiro juiz para fazer o consenso das divergências. Os protocolos foram corrigidos seguindo como referência o Sistema Compreensivo de John Exner, que é um procedimento padrão com critérios específicos para codificação de respostas (Exner, 1999; Exner \& Sendín, 1999; Weiner, 2000). A entrevista sobre História de Vida e Relações Atuais e a Entrevista 
sobre a maternidade e o relacionamento mãe-criança foram analisadas de forma qualitativa, a fim de apreender seus conteúdos e auxiliar no entendimento e discussão de cada caso. Para isso, foi aplicada a análise temática realista, uma vez que examina os temas relevantes nas entrevistas levando em conta a realidade dos participantes (Braun \& Clarke, 2006).

Após análise dos instrumentos empregados, os dados foram utilizados para organizar cada caso individualmente e construídos de acordo com os seguintes eixos de análise: a) relações iniciais e experiências traumáticas na infância; b) o puerpério e a vivência da maternidade; e c) as relações interpessoais e a relação com o bebê. Ao final, foi realizada a Síntese dos Casos Cruzados (Yin, 2001/1984) em que puderam ser discutidas semelhanças, divergências e particularidade dos achados de cada caso.

\section{Resultados}

\section{Caso 01 - Mãe Carmen, 34 anos e bebê Angélica², 9 meses}

\section{As Relações Iniciais e as Experiências Traumáticas Vividas na Infância}

Filha única, teve seus pais casados até o falecimento do pai há 5 anos. Em sua infância acredita ter sofrido de depressão e tem lembranças de ter crises de ansiedade por sentir-se angustiada. $\mathrm{O}$ relacionamento dos pais sempre foi conturbado em função do pai ser jogador compulsivo e, por isso, gastar muitas vezes o dinheiro que era para pagar as contas da casa. Lembra que a mãe tinha crises de raiva e se descontrolava, quebrando objetos pela casa na frente dela. Conta que nunca foi poupada de nada, assistindo brigas entre os pais. Sentia-se confusa e tensa pela iminência de uma nova briga. Tem lembranças de sentir-se sozinha e angustiada com a sensação de que não teria fim seu sofrimento: "Eles esqueciam de mim, né. Me deixavam lá no meu quarto, como se eu não existisse e eu lá, acordada, ouvindo tudo que acontecia e tudo que eles falam um pro outro".

\section{O Puerpério e a Experiência da Maternidade}

Quatro anos após o casamento começaram as tentativas para engravidar. Teve duas gestações em dois anos, entretanto ambas as gestações resultaram em abortos espontâneos. A partir disso, iniciou tratamento de fertilização vindo a engravidar. Relata que a gestação se desenvolveu tranquilamente, entretanto, desenvolveu diabetes gestacional no segundo trimestre da gestação. Conta que o medo de que a gestação não fosse até o final a acompanhou durante todo o tempo da gravidez.

Devido a ter Síndrome do Pânico, Carmen optou pelo parto cesárea com hora marcada, na $39^{\mathrm{a}}$ semana.
Relata que sempre houve muito desejo em ter uma filha e está feliz com a conquista, porém bastante assustada. Acredita que não estava preparada para ser mãe, pois não fazia ideia que exigiria tanta flexibilidade e segurança por parte dela.

Apesar das dificuldades, a bebê está se desenvolvendo bem. Hoje, descreve que se sente bastante angustiada e confusa com relação à criação da menina, sentindo não ser capaz de cuidá-la e que, por isso, desde seu nascimento nunca ficou sozinha com a filha, pois sente-se insegura e nervosa para isso.

Seu marido participa da rotina de cuidados da filha, contudo, apresenta humor instável. Apesar de sua mãe frequentar semanalmente sua casa, as duas têm relacionamento frio e distante. Acredita que usa bastante sua terapia para ajudar nas questões do desenvolvimento da filha, pois não quer repetir os mesmos erros que a mãe: "não quero fazer o que minha mãe fez comigo. Quero cuidar da Angélica... não dou um grito na frente dela". Recorre ao pediatra e à psicóloga às vezes para solucionar angústias cotidianas em relação à filha, como se buscasse um pai e uma mãe que pudessem dar um suporte saudável a ela em momentos de grande angústia. Carmen faz psicoterapia de orientação psicanalítica por volta de três anos e faz tratamento com psicofármacos para depressão.

\section{As Relações Interpessoais e a Relação com o Bebê}

Desde pequena sempre foi solitária. Não tinha amigos e, atualmente, segue com poucas amizades. Sobre sua relação com seus pais, lembra que era bastante apegada à mãe, mas como o pai ficava bastante tempo fora de casa, não tinha proximidade com ele. Apesar de todos os medos que cercam a maternidade, parece ser uma mãe empenhada e cuidadosa com Angélica. Relata: "eu tenho cuidado com as coisas dela. Eu sou atenta a ela. Eu não faço como minha mãe fazia"; "uma coisa que me ajuda com a Angélica é eu pensar o que minha mãe faria e daí fazer diferente disso (risos)".

Os resultados abaixo expõem os escores de Carmen na Técnica de Rorschach. Resultados acima da média são representados pelo símbolo $(\uparrow)$ e resultados abaixo da média serão representados por $(\downarrow)$. Mais adiante serão discutidos o que esses resultados expressam. $\mathrm{CDI}=2 ; \mathrm{COP}: \mathrm{AG}=0: 3 \uparrow ; \mathrm{a}: \mathrm{p}=8: 4 \uparrow ; \mathrm{Fd}=1 ; \mathrm{SumT}=0$; GHR:PHR $=2: 5 \uparrow ; \quad$ SumH $=2 ; \quad$ Isolate $/ \mathrm{R}=0,15 \downarrow$; $\mathrm{Afr}=0,39 \downarrow ; \mathrm{WsumC}=5 \downarrow ; \mathrm{EB}=4: 5$.

Diante dos resultados referentes às variáveis analisadas por meio da técnica de Rorschach, pode-se pensar que Carmen não tem dificuldade para estabelecer as relações interpessoais $(C D I)$, entretanto, pode perceber o convívio com os demais de maneira hostil ou ameaçadora $(C O P<A G)$, podendo interpretar o comportamento alheio de maneira distorcida ou agressiva $(G H R<P H R)$.

${ }^{2}$ Todos os nomes utilizados aqui são fictícios. 
Mostra-se pouco aberta às interações positivas $(H \downarrow)$, indicando pouca necessidade de proximidade e contato com as pessoas (SumT), mas ao mesmo tempo, não demonstra necessidade de se manter de maneira isolada (Isolate). Quando consegue estabelecer suas relações, pode se colocar de modo mais dependente $(F d \uparrow)$, contudo sem ser passiva $a>p$. Sua estratégia para solução de conflitos ainda é bastante confusa, oscilando entre usar a razão ou as emoções para resolvê-los, podendo ser imprevisível ou inconstante (EB ambigual). Fica evidente que, apesar de ter recursos para demonstrar seus afetos (WSumC $\uparrow$ ), evita processos psíquicos carregados de estímulos afetivos podendo, assim, sentir-se constrangida em situações de demonstração de afeto (Afr $\downarrow$ ).

\section{Caso 02 - Mãe Miriam, 35 anos e bebê Gabriela, 11 meses}

\section{As Relações Iniciais e as Experiências Traumáticas Vividas na Infância}

Os pais de Miriam se separaram quando ela estava com 5 anos e depois disso conta que a vida mudou: "um dia, quando a gente era 'pequenos' ele (o pai) foi embora e nunca mais voltou. Nunca mais". Acabou ficando a maior parte do tempo sozinha cuidando do irmão, que tinha 3 anos na época, e com o passar do tempo começou a tomar conta da casa também. Eram pobres, dependiam muitas vezes de favores da família e vizinhos para que todos comessem em casa. Ainda jovem começou a trabalhar, pois percebia que a mãe era atrapalhada com a administração do pouco dinheiro que tinham e negligente nos cuidados com os filhos. Refere ter sofrido violência física durante a infância por parte de pessoas da família que moravam no mesmo terreno que eles. Miriam faz psicoterapia de orientação psicanalítica por volta de três meses e faz tratamento com psicofármacos também. Já consultou com cinco psicólogas, mas relata que acaba sempre desistindo.

\section{O Puerpério e a Experiência da Maternidade}

Miriam e o pai de Gabriela tinham um relacionamento de 10 anos quando ela engravidou. Sempre tiveram uma relação boa e tranquila, entretanto, não era um plano do casal uma gravidez naquele momento. Quando engravidou de Gabriela, a notícia não agradou o marido, mas ela optou por levar a gestação adiante. Sendo assim, acredita que a partir dessa decisão o casal começou a se separar aos poucos: "Tudo mudou depois que eu engravidei". Muitas brigas aconteceram durante a gravidez e refere ter chorado muito e engordado quase 30 quilos devido aos altos níveis de ansiedade.

Como em sua infância, seguia com o sentimento de solidão e abandono: "Ele começou a ser frio comigo, se distanciou, me sentia sozinha...me sentia um lixo, feia, gorda e rejeitada". Nessa situação, recorre à mãe em busca de amparo e conforto emocional. O nascimento do bebê ocorreu por parto cesárea a pedido de Mirian. Depois do nascimento da filha relata que seguiu deprimida, pois percebia que o marido não mudava as atitudes com ela, tratando-a com indiferença. Quando a menina estava com cinco meses, o casal veio a se separar de forma bastante conturbada e difícil. Fica claro por meio de sua narrativa que ainda tem dificuldades em entender o porquê de acontecer a separação e chora várias vezes durante as entrevistas ao falar sobre isso. Voltou a trabalhar logo depois do nascimento da filha (2 meses), justificando que a situação financeira ficou difícil após a separação. A filha fica em casa com a avó e uma babá e parece ter uma rotina bem estabelecida. Em relação ao desenvolvimento emocional da filha, esta parece estar se desenvolvendo bem, não apresenta dificuldades de sono, alimentação, comunicação e interação social. Porém, é provável que venha reagindo às situações que o ambiente lhe apresenta, pois acabou desenvolvendo um tipo de alergia muito grave logo após a separação dos pais, sendo que hoje tem o quadro alérgico controlado, mas ainda não solucionado.

\section{As Relações Interpessoais e a Relação com o Bebê}

Atualmente tem poucas amigas, como desde pequena, mas tem relações profissionais. Sua profissão possibilita conhecer muitas pessoas e hoje seus amigos são as mesmas pessoas que são seus clientes. Conta que se determinou a lutar pelo dinheiro e ter condições de vida melhor em função do relacionamento com sua avó, pois como dependiam dela para morar no local onde moravam, isso sempre foi motivo de briga entre a avó e a mãe. Parece que hoje é a pessoa que é mais bem-sucedida na família e é possível perceber em seu discurso que, por meio da sua condição financeira, ela estabelece seus relacionamentos, seja com a família ou com os amigos. Seus familiares recorrem a ela para pedir ajuda financeira, e na maioria das vezes acaba entregando o valor pedido, justificando que faz isso porque tem pena da mãe, irmão, pai e avó.

Não tem boa relação com a mãe, mas depois da separação e do nascimento de sua filha se reaproximaram e hoje têm uma relação que nunca tiveram antes. Acredita que a mãe foi irresponsável enquanto ela e o irmão eram pequenos, mas com a neta ela tem outro comportamento, sendo disponível, cuidadosa e amorosa. Com o pai tem pouco contato e refere que a relação entre os dois é apenas de interesse e somente da parte dele, pois ela não o procura nunca: "Meu pai se tornou uma relação de interesse. Ele não significa nada pra mim”. Já ele, quando precisa de ajuda financeira, recorre a Miriam. A relação com o pai de Gabriela é bastante distante e permeada de muitas mágoas.

Durante o período da gestação trabalhou muito, pois já presumia que aconteceria a separação e queria estar amparada financeiramente. Ainda nesse período, conta que teve dificuldades de se vincular com o bebê, pois estava sobrecarregada e absorvida pelas questões do casamento: "eu não conseguia me conectar com ela... eu via 
que meu casamento tava indo ladeira abaixo e eu sem entender nada, me parei a trabalhar". Atualmente, a menina fica em casa com a avó materna e uma babá. Durante seu relato, é possível ver que um dos poucos momentos que fala mais afetivamente de alguém, é sobre a filha. Durante a entrevista sobre a maternidade teve dificuldade em manter o foco na relação com a filha, falando muito da separação do casal.

Os resultados abaixo expõem os escores de Miriam na Técnica de Rorschach. Resultados acima da média são representados pelo símbolo $(\uparrow)$ e resultados abaixo da média serão representados por $(\downarrow)$. $\mathrm{CDI}=3 ; \mathrm{COP}: \mathrm{AG}=2: 3 \uparrow ; \mathrm{a}: \mathrm{p}=9: 11 \uparrow ; \mathrm{Fd}=0 ; \mathrm{SumT}=0$;

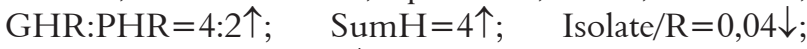
Afr $=0,50 ;$ WsumC $=1,5 \downarrow ; \mathrm{EB}=4: 1,5$

Miriam demonstra boa disponibilidade para enfrentar as demandas cotidianas do ambiente $(C D I)$. Mostra boa condição para as relações $(G H R>P H R)$ e interesse por elas $(H \uparrow)$, mas pode sentir-se pouco confortável com proximidade, necessitando manter-se a certa distância (WSumT), embora, sem necessidade de isolamento (Isolate). Assim, se posiciona de maneira desfavorável para o estabelecimento das relações $(C O P<A G)$, quando nelas, demostra tendência a agir de maneira passiva, esperando que os outros façam algo para se aproximar $(p>a+1)$. Não mostra propensão a se colocar de forma depende em seus relacionamentos (Fd). Para solução de conflitos, parece tomar decisões baseada mais em seus pensamentos do que sentimentos, preferindo a lógica para resolvê-los (EB introversivo). Apesar de ter capacidade adequada para identificar e lidar com seus afetos

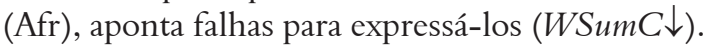

\section{Caso 03 - Mãe Raquel, 28 anos e bebê Fernando, 8 meses}

\section{As Relações Iniciais e as Experiências Traumáticas Vividas na Infância}

Raquel cresceu em uma família bastante comprometida emocionalmente. Conta que o psiquiatra com quem consulta há alguns anos acredita na hipótese de que a mãe pode ter diagnóstico de esquizofrenia e transtorno de humor bipolar, mas a própria mãe nunca consultou nenhum psiquiatra ou psicólogo. Seu pai, apesar de ser mais cuidadoso e afetuoso que a mãe com as filhas, sempre foi um homem agressivo e violento com a mãe: "lembro do pai e a mãe discutindo e batendo boca quase que o tempo todo. Elembro que o pai batia na mãe também”. Ressalta que presenciou muitas vezes cenas de discussões e agressões entre os pais.

Tem uma irmã mais velha que sempre a ajudou a enfrentar as situações pelas quais passavam juntas. Quando questionada sobre sua infância conta: "eu lembro de pouca coisa. Acho que a maioria eu esqueci de propósito" porque teve uma infância difícil e triste. Além das constantes brigas dos pais, havia sempre um clima tenso na casa devido à instabilidade de humor da mãe. A mãe não deixava que as meninas brincassem nem usassem os brinquedos que ganhavam ou que tivessem amigos, pois os cuidados da casa e da comida para a família eram obrigações das filhas.

A família não tinha contato com nenhum outro familiar, uma vez que seus pais cortaram as relações com suas famílias de origem quando optaram por casar e deixar para trás os filhos dos primeiros casamentos. A mãe deixou para trás três filhos e o pai, dois. Por incentivo de seus pais, Raquel casou-se aos 14 anos, com um homem de 24 anos, pois este tinha uma condição financeira melhor que a deles e, por isso, a mãe achava que poderia ser bom para filha. Logo após o casamento este passou a agredi-la fisicamente e violentá-la sexualmente até seus 18 anos, quando o pai tomou a iniciativa de trazer a filha para casa depois de um episódio em que viu a filha novamente tentando esconder os hematomas no corpo. Acredita que tenha iniciado o quadro de depressão ainda enquanto criança: "eu me sentia a criança mais infeliz do universo. Eu era triste... não queria mais viver. Tenho certeza que minha depressão começou na minha infância”. Raquel faz tratamento com psicoterapia de orientação psicanalítica combinada com uso de psicofármacos por volta de um pouco mais de três anos.

\section{O Puerpério e a Experiência da Maternidade}

Raquel está casada há cinco anos e Fernando foi um bebê com a vinda planejada. A gestação evoluiu tranquilamente, mas refere ter sentido as alterações de humor e teve pré-eclâmpsia no final da gestação. Correu tudo bem no parto, mas optou por não amamentar com leite materno para poder seguir tomando algumas medicações psiquiátricas. Conta que essa foi uma decisão discutida entre ela, sua psicóloga e o psiquiatra.

Sente-se segura com o marido e acredita que a gestação e a maternidade estejam sendo um pouco mais fácil por ele estar presente sempre, cuidando dela e do bebê com amor e paciência. Entende que a maternidade trouxe uma grande demanda emocional, precisando de um esforço grande para manter-se bem, pois, mesmo desejando ser mãe e tendo planejado a gravidez, sentia-se confusa e irritada. Considera que os primeiros meses foram difíceis, pois o bebê tinha cólicas e chorava, desestabilizando Raquel. Sentia-se angustiada com tanto choro e por não conseguir acalmá-lo. Entretanto, ao se atentar a isso chamava o marido para que tomasse conta do menino. Quando o marido não estava, recorria a uma vizinha que a ajudava.

Enfatiza que tenta não reproduzir com o filho o que sofreu com sua mãe, mas conta que em algumas situações perdeu o controle, repetindo o trato hostil: "sacudia ele forte pra ver se ele se assustava e parava de chorar, mas dai que ele chorava mais”. Entende que sua irritação está relacionada a sua mãe e percebe que depois da maternidade ficou mais intolerante com ela. Relata que a terapia a ajuda com as questões da maternidade. Em seu espaço individual tem 
a oportunidade de compreender melhor as necessidades do filho e ser mais assertiva nos cuidados com ele: "minha psicóloga me explicou, e eu fico bem mais aliviada quando ela me diz o que vai acontecer... é difícil pra mim às vezes enxergar as coisas como a maioria das pessoas, então ela meio que me sintoni$z a$, me dá um norte".

\section{As Relações Interpessoais e a Relação com o Bebê}

Demonstra ter poucas relações, não faz referência a nenhuma amiga ao longo das entrevistas, apenas fala da vizinha que a ajuda com o bebê, mas não parece a ter como amiga. Acredita que seu jeito para lidar com as pessoas e com o bebê é seco: "Talvez não seja uma mãe carinhosa, mas esse é meu jeito de cuidar dele também”. Logo após o nascimento do bebê, relata que teve mais dificuldade em se manter próxima e conectada com o filho, pois além do cansaço físico de cuidar de um recém-nascido, tinha a sobrecarga emocional que estava enfrentando: "Foi uma fase ruim. Meu marido chegava de noite e eu entregava o Fernando pra ele e ia dormir. Me desligava total. Na madrugada ele chorava e às vezes eu acordava, mas às vezes não". Com sua irmã tem contato mais próximo que tem com os pais, com quem mantém uma relação conturbada, oscilando entre se aproximar e se distanciar conforme as situações vão se apresentando. Com seu marido tem uma relação de muita confiança e parceria, mas refere saber que ela não é uma pessoa fácil de lidar e isso faz admirá-lo mais. Considera que ele contribui para que possa ser a mãe que é e não a recrimina ou julga quando ela perde a paciência ou se descontrola.

O relacionamento com seu filho Fernando se mostra bastante ambivalente, parecendo ser compreensiva e tolerante e irritada e com dificuldades em manter-se perto dele. Relata que se sente incomodada quando não consegue acalmá-lo. Parece que consegue desempenhar melhor os cuidados mais operacionais e conta repetidas vezes que ela, junto à psicóloga, entendem que esses cuidados também representam amor por Fernando. Entretanto, mesmo demonstrando não ter recursos para lidar com questões excessivas para seu psiquismo, demonstrar certa rigidez nas trocas afetivas com o bebê, encontrou uma maneira de estar com ele, inclusive conseguindo protegê-lo de seus ataques de fúria, pedindo ajuda ao marido quando percebe que está irritada ou sem paciência,

Os resultados abaixo expõem os escores de Raquel na Técnica de Rorschach. Resultados acima da média vêm representados pelo símbolo $(\uparrow)$ e resultados abaixo da média serão representados por $(\downarrow)$. $\mathrm{CDI}=4 ; \mathrm{COP}: \mathrm{AG}=0: 0 ; \mathrm{a}: \mathrm{p}=3: 7 \uparrow ; \mathrm{Fd}=2 \uparrow ; \mathrm{SumT}=0$; GHR:PHR $=3: 3 \uparrow ; \quad$ SumH $=4 \uparrow ; \quad$ Isolate $/ \mathrm{R}=0,13 \downarrow ;$ Afr $=0,48 ;$ WsumC $=3,5 \downarrow ; \mathrm{EB}=5: 7$

Raquel teve o Índice de Déficit Relacional positivo $(C D I)$, indicando comprometimento na capacidade de enfrentar as demandas cotidianas, podendo interferir em sua adaptação, em geral no âmbito social, tendendo a ser mais superficial e menos empática. Não atribui às relações nem aspectos negativos, nem positivos ( $A G$ :COP), o que pode ter a ver com sua dificuldade na manutenção das relações (GHR:PHR), gerando pouca necessidade de contato (SumT). Não há indicativos de necessidade de isolamento (Isolate) e mostra desejo pelas relações interpessoais $(H \uparrow)$, apesar de não colaborar muito para que elas aconteçam $(p>a+1)$. Quando estabelecidas, suas relações mostram elevado nível de dependência emocional, podendo ter condutas passivo-dependentes $(F d)$. Os dados sugerem que prefere usar a lógica para tomar decisões, deixando seus sentimentos à margem (EB introversivo), mesmo mostrando ter condições para interagir e expressar suas emoções (WSumC).

\section{Discussão}

Ao focar nas relações interpessoais, é necessário voltar a atenção à origem da vida, buscando por entender como foram as relações iniciais. Assim, após análise dos resultados de todos os instrumentos foi possível chegar a alguns pontos relevantes que serão discutidos adiante em cada eixo proposto:

\section{As Relações Iniciais e as Experiências Traumáticas Vividas na Infância}

Os efeitos da exposição precoce a vivências traumáticas acarretam prejuízos no desenvolvimento emocional do indivíduo, conforme extensa literatura (Allen, 2012; Berthelot et al., 2015; Schumm, Briggs-Phillips, \& Hobfoll, 2006). Em seu estudo de Van der Kolk (2005) identifica fatores como a instabilidades das relações parentais e a s exposição a situações traumáticas, como fatores que podem gerar alterações na capacidade para desenvolver relacionamentos, assim como pode modificar a percepção que essas crianças têm das pessoas, das relações e do mundo de uma maneira geral dificultando a capacidade de formar novos vínculos.

As participantes viveram sucessivas rupturas em suas relações e carregam a marca de terem sido expostas a situações de agressões, violência e medo da morte e deixando registros, conscientes e inconscientes, que interferem na vida adulta, nas relações interpessoais e na relação com seus bebês hoje. Conforme Winnicott (1999/1987), o bebê necessita do rosto da mãe, de suas atitudes faciais, de seu olhar, do ambiente para constituir-se enquanto pessoa. Dessa forma, a função da mãe, do pai, e do ambiente é proteger, cuidar e amar, ou seja, fazer exatamente o contrário do que parecem ter vivenciado essas participantes. Pode-se supor que os modelos de identificação e suas relações iniciais foram internalizados como objetos ruins, tornando as relações de confiança fragilizadas e fragmentadas. Dessa forma, a capacidade de exercer a maternidade com seus bebês parece que também fica prejudicada. A seguir, alguns pontos relevantes serão discutidos em que é possível perceber esses prejuízos: 


\section{O Puerpério e a Experiência da Maternidade}

Todas referem que não se sentiam amadas em suas infâncias, sendo acompanhadas pelos sentimentos de solidão, desamparo e desvalia. Sentiram a maternidade como um misto de amor e esperança pela relação nova que se inaugura com o bebê, mas também momento de dor e sofrimento, remetendo-as a um tempo ruim. A literatura aponta que a capacidade de o cuidador ser sensível ou não está diretamente relacionada com a história de seus próprios vínculos iniciais (Bowlby, 1990).

A vivência da maternidade para a mulher é um momento no qual inevitavelmente emergem situações emocionais anteriormente encobertas e/ou não totalmente solucionadas da sua vida, aflorando conteúdos inconscientes (Klaus et al., 2000; Maldonado, 2002). É um período no qual ela pode passar por uma espécie de regressão psíquica, relembrando e revivendo experiências com sua própria mãe.

Todas elas referem que sentiram muitas dificuldades em relação à maternidade. Talvez pelo fato de que o inconsciente da mãe, quando tem em suas memórias e lembranças um objeto cuidador bom e amável introjetado, tende a se identificar com seu bebê e assim responder melhor às suas demandas, reconhecendo melhor suas vontades e podendo proporcionar segurança e proteção a ele (Winnicott, 1999/1987). Da mesma forma, vale para o contrário, é pouco provável que a mãe que não viveu um encontro prazeroso e saudável com sua própria mãe, consiga se conectar e encontrar sintonia com seu bebê.

Aqui as três participantes não usufruíram dessas relações e hoje demonstram ter dificuldade para se relacionarem com seus bebês. Nesses casos, em função dos traumas vividos, parece que as mães tomaram suas mães como um modelo, entretanto, um modelo a não ser seguido. É possível ver que tiveram dificuldade para entender seus bebês, em se vincular com eles e para se adaptar com respeito ao ritmo e necessidade da criança. Raquel ficava muito angustiada quando não conseguia se comunicar, entender e acalmar o filho e, por isso, acabava delegando-o a sua rede de apoio. Carmen em muitos momentos teve sua ansiedade tão elevada que não conseguia perceber as necessidades da filha. E Miriam teve que fazer um árduo trabalho psíquico, para ao mesmo tempo gestar a filha e viver o luto pelo seu casamento que percebia que estava chegando ao fim.

Também foi possível identificar que o fato de todas as participantes fazerem psicoterapia sem dúvida auxiliou-as a enfrentar o puerpério e a maternidade. Carmen e Raquel ressaltam essa questão em seus relatos. A relação de troca e confiança estabelecida com a terapeuta, com pediatra e com o marido ajudam essas mulheres a construir e a desenvolver o papel materno dentro de cada uma. O tratamento aparece como um lugar de segurança, na qual a sensação de estar sendo acompanhando na árdua empreitada que é a maternidade, tenha permitido a elas, tornarem-se mães. Um terapeuta sensível, empático e verdadeiro pode contribuir muito com essas pacientes, uma vez que elas precisam passar pela experiência de viver uma relação de confiança, onde possam sentir-se acolhidas, compreendidas e atendidas.

\section{As Relações Interpessoais e a Relação com o Bebê}

Por meio de seus relatos, foi possível identificar que todas têm como dificuldade central o medo da rejeição nas relações. De acordo com Mitchell (2000), pessoas que passam por situações traumáticas ainda na infância têm dificuldade em expor seus sentimentos e construir vínculos, pois acreditam que manter uma relação amorosa e íntima é algo ameaçador, podendo ser a causa de desconforto emocional.

$\mathrm{Na}$ história de Carmen, é possível identificar que existe uma relação bem próxima e íntima com a filha, talvez os cuidados e atenção que recebeu de sua avó quando criança tenha a salvado de se desenvolver na solidão e tenha conseguido criar um vínculo seguro a ela. Entretanto, a maternidade faz com que reviva experiências decorrentes das falhas ambientais vividas na sua infância e acabam a remetendo, talvez a mesma sensação que tinha quando pequena, desamparo e insegurança, porém agora frente à sua bebê.

A participante Miriam parece terceirizar bastante os cuidados de sua filha, assim como aconteceu na sua história. É como se a falta de investimento de amor de sua mãe tenha deixado marcas e desesperanças em sua capacidade de trocar, relacionar-se e se comunicar, fazendo com que ela acredite que tudo isso está ligado à sua maneira de ser. Nos seus relatos fica clara a dificuldade de formar e manter as pessoas próximas.

Raquel, que parece ter uma relação mais distante das pessoas, apresenta dificuldade nas trocas de afeto com seu bebê, sendo um pouco distante afetivamente, entretanto com ajuda de sua psicóloga vem conseguindo ter uma relação de cuidado, proteção e amor. Ainda que, em algumas vezes relata ter rompantes de agressividade, consegue perceber sua limitação e pedir ajuda, ou para a vizinha, ou para o marido. É uma atitude de cuidado com Fernando. Assim como quando opta por não o amamentar com leite materno, por causa das medicações que toma, em prol de manter sua saúde mental e sabendo dos benefícios disso para seu bebê. Assim, demonstra que tem consciência dos malefícios de expor Fernando a seus ataques de fúria, entretanto sua capacidade simbólica pode ter sido afetada trazendo falhas produzidas pela instabilidade do ambiente (família).

Os dados obtidos por meio do Rorschach foram analisados de acordo com os escores individuais comparados às médias brasileiras - estatística descritiva para 409 protocolos de paulistanos não pacientes, uma vez que as médias mudam de acordo com cada cultura e país (Nascimento, 2010). As variáveis avaliadas aqui são aquelas que se acredita que podem responder às questões do estudo. 
Tabela 1

Resultados das Participantes e Estatística Descritiva para 409 Protocolos de Acordo com Amostra Brasileira (Nascimento, 2010)

\begin{tabular}{|c|c|c|c|c|c|c|c|c|c|}
\hline Variáveis & Caso 1 & Caso 2 & Caso 3 & Média & Desvio padrão & Mínimo & Máximo & Mediana & Moda \\
\hline \multicolumn{10}{|c|}{ Variáveis do Relacionamento Interpessoal } \\
\hline CDI & 2 & 3 & 4 & & & & & & \\
\hline COP & 0 & 2 & 0 & 0,68 & 0,91 & 0,00 & 4,00 & 0,00 & 0,00 \\
\hline AG & 3 & 4 & 0 & 0,29 & 0,63 & 0,00 & 4,00 & 0,00 & 0,00 \\
\hline A & 8 & 9 & 3 & 3,79 & 2,68 & 0,00 & 18,00 & 3,00 & 3,00 \\
\hline $\mathrm{P}$ & 4 & 11 & 7 & 3,86 & 2,56 & 0,00 & 16,00 & 3,00 & 3,00 \\
\hline $\mathrm{Fd}$ & 1 & 0 & 2 & 0,30 & 0,59 & 0,00 & 4,00 & 0,00 & 0,00 \\
\hline GHR:PHR & $2: 5$ & $4: 2$ & $3: 3$ & & & & & & \\
\hline $\mathrm{H}$ & 2 & 4 & 10 & 1,92 & 1,59 & 0,00 & 9,00 & 2,00 & 1,00 \\
\hline Isolate & 0,15 & 0,04 & 0,13 & 0,22 & 0,16 & 0,00 & 0,86 & 0,20 & 0,00 \\
\hline \multicolumn{10}{|c|}{ Variáveis do Afeto } \\
\hline WSumT & 0 & 0 & 0 & 0,41 & 0,76 & 0,00 & 4,00 & 0,00 & 0,00 \\
\hline Afr & 0,39 & 0,50 & 0,48 & 0,55 & 0,23 & 0,20 & 1,75 & 0,50 & 0,50 \\
\hline WSumC & 5 & 1,5 & 3,5 & 2,19 & 1,81 & 0,00 & 11,50 & 2,00 & 0,00 \\
\hline EB & 4:5 & $4: 1,5$ & $5: 3,5$ & & & & & & \\
\hline
\end{tabular}

Esses índices obtidos por meio da avalição do Rorschach vão ao encontro do que foi revelado pelas participantes através dos seus relatos quando questionadas sobre a relação com seus primogênitos. As dificuldades que se sobressaíram em seus relatos foram inabilidade em compreender as demandas dos bebês, pouca tolerância ao estresse, resistência com as emoções e em expressar seus afetos pelos bebês, sentimentos ambivalentes em relação à maternidade e descrédito em relação às próprias percepções sobre os filhos, julgando que outras pessoas sabem mais deles do que elas mesmas. Todas referem que a maternidade trouxe sentimentos, como medo, ansiedade e um misto de alegria pelo bebê, mas de tristeza pelas lembranças da infância ocasionadas com a chegada do primeiro filho.

Por fim, pode-se concluir que a maternidade se constitui de uma experiência interior única, solitária e profunda na qual a mulher fica entregue às suas sensações internas, fantasias, marcas e lembranças. Para tanto, é necessário que haja uma espécie de reencontro com sua mãe interna. Golse e Bydlowski (2002) acreditam que quando o objeto interno da mãe é constituído de vivências traumáticas e ameaçadoras, pode trazer angústias e sensações desconfortáveis com a chegada da maternidade. A importância de a atenção estar focada nas relações interpessoais está no fato de que é por meio delas que se originam as primeiras relações de um indivíduo, ou seja, é no contato com a mãe e familiares que a criança aprende a se relacionar com as pessoas e com o mundo (Bowlby, 1990/1969; Georgiou \& Meins, 2010; Khoshkam, Bahrami, Ahmadi, Fatehizade, \& Etemadi, 2012).

Ao mesmo tempo em que as situações traumáticas geram dificuldades emocionais, elas também puderam gerar nesses casos um desejo em não repetir as histórias na construção de suas próprias famílias. A maternidade talvez propicie esse processo de busca pela mudança ou melhora. Sendo assim, pode se entender a psicoterapia como um canal de ajuda para ressignificar lembranças ruins e traumáticas, proporcionando segurança para essas mulheres desenvolverem-se enquanto mãe (Golse \& Bydlowski, 2002). Sem dúvida é um caminho desconfortável em muitos momentos, porém talvez seja o único que oferece a possibilidade, de finalmente, deixar a prisão da infância.

Por meio dos relatos obtidos, as dificuldades encontradas nos relacionamentos interpessoais das participantes foram identificadas também na relação com seus filhos. São mães com desejo de proporcionar uma relação diferente daquela que viveram em suas infâncias, entretanto, apesar da intenção benevolente, todas apresentam falhas significativas no estabelecimento e manutenção das relações de proximidades com as pessoas, mostrando desconfiança com as relações e pouco interesse em manter-se em contato com os demais.

Por fim, justifica-se que as condutas e os comportamentos das participantes com seus bebês não foram observados e nem medidos diretamente, sendo essa uma limitação deste estudo. Esses dados foram coletados por meio dos relatos obtidos nas entrevistas aplicadas aqui. Assim, sugere-se estudos que tenham como foco acompanhar e avaliar a interação da dupla ao longo do primeiro ano ou em outras etapas do desenvolvimento.

\section{Agradecimentos}

Não há menções.

\section{Financiamento}

A presente pesquisa não recebeu nenhuma fonte 
de financiamento sendo custeada com recursos dos próprios autores.

\section{Contribuições dos autores}

Todos os autores contribuíram substancialmente para a elaboração do delineamento da pesquisa, análise e interpretação dos dados, bem como, para a revisão textual e aprovação da versão final deste estudo. Todos os autores assumem responsabilidade pública pelo conteúdo do manuscrito.

\section{Disponibilidade dos dados e materiais}

Todos os dados e sintaxes gerados e analisados durante esta pesquisa serão tratados com total sigilo devido às exigências do Comitê de Ética em Pesquisa em Seres Humanos. Porém, o conjunto de dados e sintaxes que apoiam as conclusões deste artigo estão disponíveis mediante razoável solicitação ao autor principal do estudo.

\section{Conflito de interesses}

Os autores declaram que não há conflitos de interesses.

\section{Referências}

Allen, J. G. (2012). Restoring mentalizing in attachment relationships: Treating trauma with plain old therapy. Arlington: American Psychiatric Publishing.

Berthelot, N., Ensink, K., Bernazzani, O., Normandin, L., Luyten, P., \& Fonagy, P. (2015). Transmissão intergeracional do apego em mães abusadas e negligenciadas: o papel do funcionamento reflexivo específico do trauma. Revista de saúde mental infantil, 36(2), $200-212$.

Bowlby, J. (1990). Apego e perda: Apego, a natureza do vínculo (Vol. 1). São Paulo: Martins Fontes. (Obra original publicada em 1969).

Braun, V., \& Clarke, V. (2006). Using thematic analysis in psychology. Qualitative research in psychology, 3(2), 77-101. Recuperado de http:// www.tandfonline.com/doi/abs/10.1191/1478088706qp063oa

Conselho Nacional de Saúde. (2016). Resolução no 510/2016. Recuperado em 31 de outubro de 2017, de <http://conselho.saude.gov.br/ resolucoes/2016/Reso510.pdf>

Dias, E. O. (2012). A teoria do amadurecimento de D. W. Winnicott (2nd ed). São Paulo: DWW Editorial.

Exner, J. E. (1999). Manual de classificação do Rorschach para o Sistema Compreensivo. São Paulo: Casa do Psicólogo.

Exner, J. E. (2003). The Rorschach: A Comprehensive System - Basic foundations and principles of interpretation (Vol. 1). New Jersey: John Wiley and Sons.

Exner, J. E., \& Sendín, C. (1999). Manual de interpretação do Rorschach para o Sistema Compreensivo. São Paulo: Casa do Psicólogo.

Felice, E. M. (2007). Transformação e "cura" através da experiência de ser mãe. Psychê, 11(21), 145-159. Recuperado de http://pepsic.bvsalud. org/pdf/psyche/v11n21/v11n21a10.pdf

Georgiou, M., \& Meins, E. (2010). Relations between peer attachment, self-esteem, and perceived parental bonding in Greek Cypriot and British Young Adults. The Cyprus Review, 22(1), 61-77. Recuperado de http://cyprusreview.org/index.php/cr/article/view/182

Golse, B., \& Bydlowski, M. (2002). Da transparência psíquica à preocupação materna primária: Uma via de objetalização. Em L. Correiafilho, M. E. Corrêa \& P. S. França (Orgs.), Novos olhares sobre a gestação e a criança até três anos: Saúde perinatal, educação e desenvolvimento do bebê (pp. 215-220). Brasília: LGE.

Kerr-Corrêa, F., Tarelho, L. G., Crepaldi, A. L., Camiza, L. D., \& Villanassi, R. (2000). Abuso sexual, transtornos mentais e doenças físicas. Revista de Psiquiatria Clínica, 27(5), 257-271. Recuperado de https://repositorio.unesp.br/handle/11449/66408

Khoshkam, S., Bahrami, F., Ahmadi, S. A., Fatehizade, M., \& Etemadi, O. (2012). Attachment Style and Rejection Sensitivity: The Mediating Effect of Self-Esteem and Worry among Iranian college students. Europe's Journal of Psychology, 8(3), 363-374. doi: 10.5964/ ejop.v8i3.463

Klaus, M. H., Kennel, J. H., \& Klaus, P. H. (2000). Vinculo: Construindo as bases para um apego seguro e para a independência. Porto Alegre: Artmed.

Luthar, S., \& Cicchett, D. (2000). The construct of resilience: Implications for interventions and social policies. Development and Psychopatholy, 12(4), 857-885. doi: 10.1017/S0954579400004156

Maldonado, M. T. (2002). Psicologia da gravidez: Parto e puerpério (16th ed.). São Paulo: Saraiva.

McWey, L. M., Cui, M., \& Pazdera, A. L. (2010). Changes in externalizing and internalizing problems of adolescents in foster care. Journal of Marriage and Family, 72(5), 1128-1140. doi: 10.1111/j.1741-3737.2010.00754.x

Mitchell, S. A. (2000). The origin and nature of the "object" in the theories of Klein and Fairbairn. Em J. S. Grotstein \& D. B. Rinsley (Orgs.), Fairbairn and the origins of object relations (pp. 66-87). New York: Other Press.

Nascimento, R. S. G. F. (2010). Sistema Compreensivo do Rorschach: Teoria, pesquisa e normas para a população brasileira. São Paulo: Casa do Psicólogo.

NUDIF (2008). Entrevista sobre experiência da maternidade. Instituto de Psicologia - UFRGS, Porto Alegre. Instrumento não publicado.

Schumm, J. A., Briggs-Phillips, M., \& Hobfoll, S. E. (2006). Cumulative interpersonal traumas and social support as risk and resiliency factors in predicting PTSD and depression among inner-city women. Journal of Traumatic Stress, 19(6), 825-836. doi: 10.1002/jts.20159

Van der Kolk, B. (2005). Developmental trauma disorder. Psychiatric Annals, 35(5), 401-408. doi: 10.3928/00485713-20050501-06

Weiner, I. B. (2000). Princípios da interpretação do Rorschach. São Paulo: Casa do Psicólogo.

Winnicott, D. W. (1990). Natureza Humana. Rio de Janeiro: Imago. (Obra original publicada em 1988). 
Winnicott, D. W. (1999). Os bebês e suas mães. São Paulo: Martins Fontes. (Obra original publicada em 1987).

Yin, R. K. (2001). Estudo de caso: Planejamento e métodos. Porto Alegre: Bookman. (Obra original publicada em 1984).

\section{Sobre as autoras}

Maira Noroefé dos Santos é psicóloga clínica, especialista em psicoterapia de orientação psicanalítica para o atendimento de crianças, adolescentes e adultos e em teoria e técnica de intervenção na relação pais-bebê. Mestre em psicologia Clínica pela Universidade do Vale do Rio dos Sinos.

Tagma Marina Schneider Donelli é psicóloga, doutora em Psicologia pela Universidade Federal do Rio Grande do Sul, professora e pesquisadora do Programa de Pós-graduação em Psicologia, com ênfase em Psicologia Clínica, da Universidade do Vale do Rio dos Sinos.

\section{Como citar este artigo}

Santos \& Donelli (2020). Traumas Infantis e as Relações Interpessoais e com o Bebê no Puerpério. Avaliação Psicológica, 19(3), $244-253$. http://dx.doi.org/10.15689/ap.2020.1903.17037.03 